\title{
TABLAS LOGARITMICAS
}

PARA

QUIMICOS, FARMACEUTICOS, MÉDICOS

$Y$ FÍSICOS 



\title{
TABLAS LOGARÍTMICAS
}

PARA

\section{QUIMIICOS, FARMACÉUTICOS, MÉDICOS Y FísICOS}

\section{ASÍ COMO PARA LABORATORIOS DE ENSEÑANZA}

Y PARA LOS INDUSTRIALES

\author{
PUR EL \\ Prof. Dr. F, W. KUSTER † \\ adaptadas al ESTAdo actual de la ciencia \\ POR EL \\ Dr. A. THIEL \\ Profesor de Quimica-fisica y Director de \\ Instituto Quimico-fisico de la Universidad de Marburg \\ SEGUNDA EDICIÓN ESPAÑOLA \\ TRAdUCida DE LA $51^{\text {a }}$ A $55^{a}$ Edicion Alemana \\ POR \\ JUAN MERCADAL \\ Ingeniero quimico
}

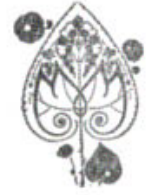

MANUEL MARIN, EDITOR

Provenza, 273. - BARCEI.ONA

1943 


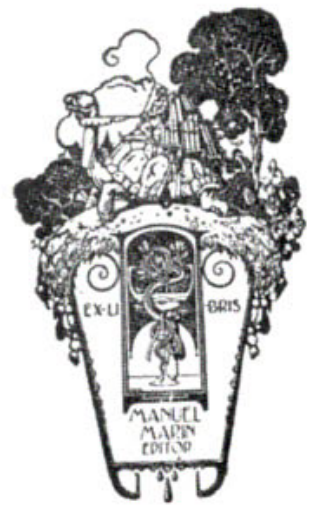

RESERVADOS TOLOS TOS DERECHOS QUEDA HECHO EL DEPOSITO QUE ORDENA LA LEY COPYRIGHT 1943, BY MANUEL MARIN, WÁSHINGION

PRINTID IN SPAIN 